\title{
Characterization of the Key Aroma Compounds in Traditional Hunan Smoke-Cured Pork Leg (Larou, THSL) by Aroma Extract Dilution Analysis (AEDA), Odor Activity Value (OAV), and Sensory Evaluation Experiments
}

\author{
Dandan Pu ${ }^{1,2}$, Yuyu Zhang ${ }^{1, *}{ }^{\mathbb{D}}$, Huiying Zhang ${ }^{1}$, Baoguo Sun ${ }^{1}$, Fazheng Ren ${ }^{2}$, Haitao Chen ${ }^{1}$ \\ and Yizhuang Tang ${ }^{1}$ \\ 1 Beijing Key Laboratory of Flavor Chemistry, Beijing Technology and Business University (BTBU), \\ Beijing 100048, China; 18518351472@163.com (D.P.); zhanghuiying@btbu.edu.cn (H.Z.); \\ sunbg@btbu.edu.cn (B.S.); chenht@th.btbu.edu.cn (H.C.); yizhuang.tang@foxmail.com (Y.T.) \\ 2 Beijing Advanced Innovation Center for Food Nutrition and Human Health, College of Food Science \& \\ Nutritional Engineering, China Agricultural University, Beijing 100083, China; renfazheng@cau.edu.cn \\ * Correspondence: zhangyuyu@btbu.edu.cn; Tel./Fax: +86-010-68985382
}

Received: 2 March 2020; Accepted: 19 March 2020; Published: 2 April 2020

check for updates

\begin{abstract}
The key aroma compounds in smoke-cured pork leg were characterized by gas chromatography-olfactometry coupled with aroma extract dilution analysis (GC-O/AEDA), odor activity value (OAV), recombination modeling, and omission tests. Ranking analysis showed that pork leg smoke-cured for 18 days had the best sensory qualities, with strong meaty, smoky, roasty, woody, and greasy attributes. Thirty-nine aroma-active regions with flavor dilution (FD) factors ranging from 9 to 6561 were detected. Overall, 3-ethylphenol had the highest FD factor of 6561, followed by 2,6-dimethoxyphenol, 3,4-dimethylphenol, 4-ethylguaiacol, 4-methylguaiacol, 3-methylphenol, and 2-acetyl-1-pyrroline, with FD $\geq 243$. Among 39 aroma compounds, 27 compounds with OAVs $\geq 1$ and were potent odorants. A similarity of $90.73 \%$ between the recombination model and traditional Hunan Smoke-cured Pork Leg (THSL) sample was obtained. Omission tests further confirmed that (E)-2-nonenal, 2-methoxy-4-vinylphenol, guaiacol, 3-ethylphenol, 2,6-dimethylphenol, 2-acetyl-1-pyrroline, and methional were key odorants in smoke-cured pork leg. Additionally, 2-acetyl-1-pyrroline $(38.88 \mu \mathrm{g} / \mathrm{kg})$, which contributes to a roasty aroma, was characterized here as a key odorant of smoke-cured pork leg for the first time.
\end{abstract}

Keywords: traditional Hunan smoke-cured pork leg; gas chromatography-olfactometry; aroma compounds; recombination and omission test

\section{Introduction}

Pork is an important source of food that provides rich nutrients, such as protein and fat. The production of pork reached 5415 tons globally in 2018, and its consumption in China reached $40 \mathrm{~kg} /$ capita/year (data from the China Industry Information Network, May 2019). Compared to fresh pork, smoke-cured pork has a richer aroma, a smoky and savory aroma that is considered to be unique. Smoke-cured processing extends the shelf-life and enhances the flavor quality of meat products [1]. Hunan smoke-cured meat, with its bright red color and strong smoky and savory aroma, is one of the most famous smoke-cured meats in China. There are two kinds of Hunan traditional smoke-cured meat products: smoke-cured bacon and smoke-cured pork leg (THSL). The processing procedures for THSL include meat cutting and trimming, salt-curing, hang-drying, smoke-curing, and packaging. 
Smoke-curing is the main process that plays an important role in the generation of the meat's unique smoky and savory aroma. Aroma is the key factor that decides the sensory quality of the food and its appeal to consumers [2]. During the production of smoke-cured meat, many aroma compounds are generated through microbial fermentation [3,4], lipid oxidation [5-7], the Maillard reaction, and Stecker degradation [3]. These aroma compounds contribute to the aroma profiles of smoke-cured meat products.

More than 400 volatile compounds in smoke-cured meat products have been reported in previous studies. It is widely known that not all volatile compounds in foods contribute to their aromas. Only a small number $(\sim 1-3 \%)$ of such compounds can be detected as key odorants by human olfactory receptors, which results in aroma perception [8]. By applying gas chromatography-olfactometry (GC-O) coupled with the frequency method, 3-ethylphenol, guaiacol, furfuryl alcohol, 2,5-dimethlpyrazine, $(E, E)$-2,4-decadienal, and methional were identified as key odorants in smoke-cured mini-pig [6]. In addition, 2-methyl-3-(methyldithio)furan, 2-methyl-3-furanthiol, guaiacol, and 1-octen-3-one were characterized as the most potent odorants in smoked cooked loin by GC-O coupled with aroma extraction dilution analysis (AEDA) [9]. In our previous study, 2-methylpyrazine, 3-methyl-2-cyclopenten-1-one, nonanal, 5-methyl furfural, benzaldehyde, guaiacol, and eugenol were characterized by GC-O as aroma-active compounds in industrially produced Hunan smoke-cured bacon [10]. Using solid-phase microextraction (SPME), Yu and co-workers identified 27 and 43 volatile compounds, including four phenolic compounds in Hubei smoke-cured bacon with different fiber coatings [11,12]. Moreover, the regularity of changes in aroma during the smoke-curing process for Hunan smoke-cured meat and Chongqing smoke-cured meat was analyzed by SPME coupled with gas chromatography-mass spectrometry (GC-MS) analysis and simultaneous distillation extraction (SDE) coupled with GC-MS analysis, respectively $[13,14]$. During the smoke-curing process, there is a significant increase in the concentrations of phenolic and carbonyl volatiles-the major aroma compounds in Hunan smoke-cured bacon $[14,15]$. Saldaña and co-workers reported that "woody" and "pleasant" aroma attributes correlated with a high number of related volatile compounds, mainly aldehydes, phenols, and ketones [16]. Moreover, some volatile compounds, such as (E,E)-3-octen-2-one, 2-octenal and $(E)$-2-tridecenal, are responsible for the rancid off-flavor of smoke-cured meat during storage [17]. Although many related studies have been conducted, most of them have focused on the composition and the identification of volatile constituents and how these generally change during smoke-curing processing including the effects of different smoke-cured woods on the volatile compounds and their aroma profile properties [18,19]. Many of the key aroma compounds in smoke-cured meat products remain to be identified. Key odorants are the main reference compounds used to clarify the quality differences between different brands of food and are also the marker compounds used to monitor quality during food production. Moreover, the characterization of key aroma compounds could provide a way to modify or change the manufacturing process of smoke-cured pork leg [20].

Therefore, the objective of this work was to identify the key aroma compounds in THSL by using a systematic approach including the (1) isolation of volatile compounds by simultaneous distillation extraction (SDE); (2) identification of aroma-active compounds by GC-O-MS/AEDA; (3) quantification of aroma-active compounds through construction of standard curves and calculation of the odor activity values (OAVs); and (4) validation and confirmation of key odorants by recombination modeling and omission experiments.

\section{Materials and Methods}

\subsection{Sample Preparation}

The THSL was produced in Huaihua, Hunan province, China. The specific preparation steps for the THSL sample are shown in Figure 1. The pork leg (Duroc pig, Hunan white pigs line 1) was purchased from a local farmer (Huaihua, China). The pork leg was cut into pieces ( $\sim 4-5 \mathrm{~cm}$ in width, 
$\sim 40-50 \mathrm{~cm}$ in length) and trimmed. These pieces were then salt-cured (using 35:2 mass ratio of meat to salt) for 7 days. After $6 \mathrm{~h}$ of hang-drying to drain out the blood and water, the salt-cured sample was smoke-cured by burning the stem portion of dried Camellia oleifera Abel sticks $(\sim 50-55 \mathrm{~cm})$ at a temperature of $26.55 \pm 1.24{ }^{\circ} \mathrm{C}$ and humidity of $53.31 \% \pm 14.58 \%$ for $30 \mathrm{~d}$. The concentration of smoke (PM $2.5=0.57 \pm 0.39 \mathrm{mg} / \mathrm{m}^{3}$, PM $10.0=2.40 \pm 0.38 \mathrm{mg} / \mathrm{m}^{3}$ ) was monitored using a PC-3A Dust Instrument (Qingdao, YiLan Environment, China) during the smoke-curing process. During the smoke-curing process, the THSL sample was sampled daily (coded THSL-1, THSL-2, ... , and THSL-30) using triplicates for each sample.

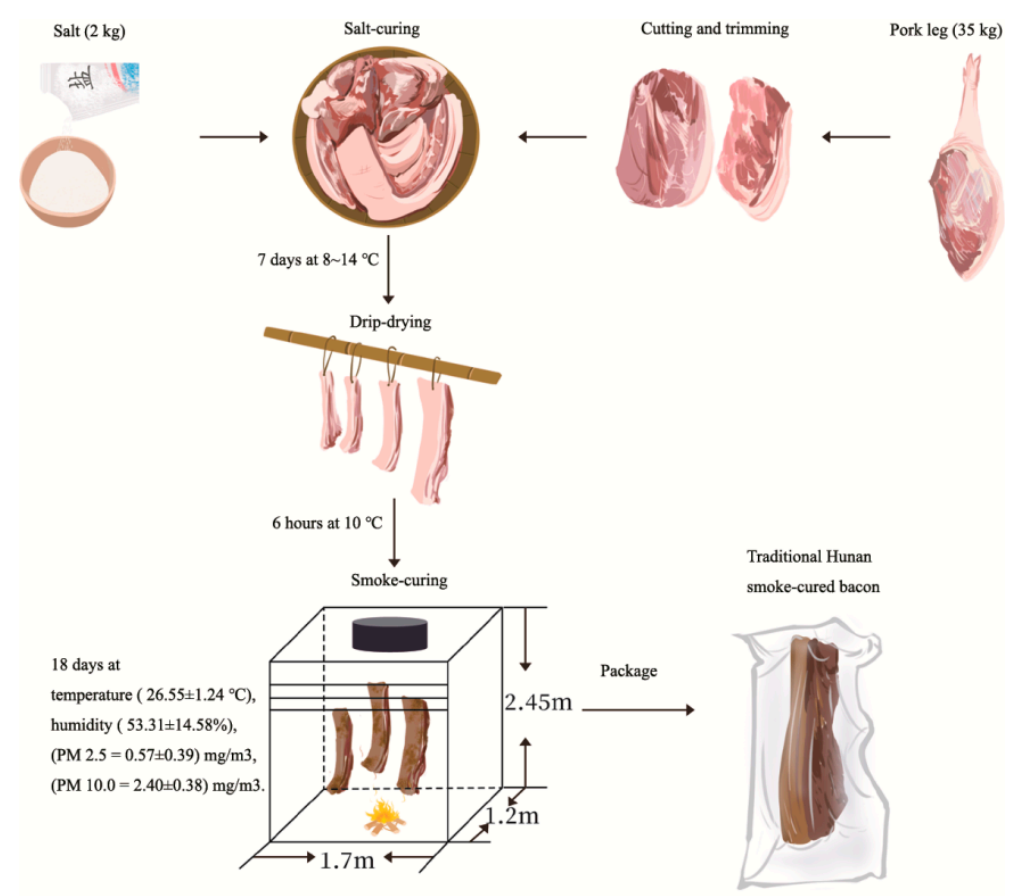

Figure 1. Steps for the preparation of traditional Hunan smoke-cured pork leg (THSL).

\subsection{Chemicals}

Dichloromethane and 1,2-dichlorobenzene (HPLC grade) were purchased from Thermo Fisher (Beijing, China). 2-Ethylnaphthalene, 2-methylnaphthalene, 3-ethyl-2-hydroxy-2-cyclopenten-1-one, 1-methylnaphthalene, 2,3,5-trimethylpyrazine, octanal, guaiacol, 5-methyl furfural, 3-methyl-2cyclopenten-1-one, 2-methylpyrazine, 2-methylphenol, 3-methylphenol, 2-acetyl-1-pyrroline, and methional with a purity over $99 \%$ were purchased from J\&K (Beijing, China). 3-Methylacetophenone, (E)-2-octenal, 1-octen-3-one, 3,4,5-trimethoxytoluene, 3,4-dimethyltoluene, 2-methoxy-4-vinylphenol, 2-acetylfuran, 3,4-dimethyphenol, 2-methoxy-4-propyl-phenol, and (E)-2-nonenal of 97\% purity were purchased from Alfa (Beijing, China). 2,6-Dimethoxyphenol, 2,6-dimethylphenol, 3,5-dimethoxyphenol, 2,3-dimethoxyphenol, 2,5-dimethylphenol, and 4-ethylguaiacol with purity over 95\% were purchased from Acros (Beijing, China). 4-Methylguaiacol and 3-ethylphenol with 99\% purity were purchased from Ark (Beijing, China). Food grade edible salt was purchased from the China Salt Industry Corporation (Beijing, China), and the dried stem portion of Camellia oleifera Abel was purchased from a local supermarket (Huaihua, China). Capric triglyceride was purchased from Nanjing Kangmanlin Chemical Industry Co., Ltd. (Nanjing, China).

\subsection{Sensory Evaluation Analysis}

A ranking analysis and quantitative descriptive analysis methods were used in this study. The sensory evaluation was performed by 15 experienced panelists ( 6 males and 9 females aged 23-28, healthy, without rhinitis, and nonsmokers) recruited from our laboratory. Before evaluation of the 
THSL sample, the panelists were trained to distinguish and describe the aroma characteristics of 32 pure standards (Section 2.2). Each of the standards was dissolved in the odorless ultra-pure capric triglyceride solution at a concentration of $10 \mathrm{mg} / \mathrm{L}$. After 3 weeks of training (sessions held once per week), the panelists proceeded to conduct sensory evaluation of the THSL sample. Firstly, the ranking analysis was conducted by asking the panelists to sort the THSL samples according to their preferences. The 30 smoke-cured THSL samples were divided into 5 groups (THSL-1 to THSL-6; THSL-7 to THSL-12; THSL-13 to THSL-18; THSL-19 to THSL-24; and THSL-25 to THSL-30). The panelists were asked to select the 2 best samples from each group. Finally, the panelists' favorite THSL sample was selected from the 10 THSL samples according to selection frequency.

The THSL sample with the best sensory quality $(5 \mathrm{~g})$ was cut into pieces $(\sim 1-2 \mathrm{~mm})$ and loaded into an odorless transparent plastic bottle $(30 \mathrm{~mL})$ which was then presented to the panelists. A unique and random four-digit number written on paper was pasted onto the sample bottle for identification. The panelists were asked to analyze the THSL sample using the 7 sensory attribute profiles (woody, smoky, meaty, milky, greasy, roasty, and spicy) as determined by the sensory evaluation group. The sensory descriptors were evaluated in comparison to capric triglyceride solutions of the corresponding reference odorants: meaty (2-methyl-3-furanthiol, $10 \mathrm{mg} / \mathrm{L})$, greasy $((E, E)-2,4$-decadienal, $20 \mathrm{mg} / \mathrm{L})$, milky (2,3-butanedione, $10 \mathrm{mg} / \mathrm{L}$ ), woody (guaiacol, $50 \mathrm{mg} / \mathrm{L}$ ), smoky (2,6-dimethylphenol, $20 \mathrm{mg} / \mathrm{L}$ ), roasty (2-acetyl-1-pyrroline, $10 \mathrm{mg} / \mathrm{L}$ ), and spicy (4-guaiacol, $50 \mathrm{mg} / \mathrm{L}$ ). Each of the attributes was evaluated on a nine-point scale (1-3, weak; $4-6$, medium; $7-9$, strong) according to the reference standards. All experiments were repeated three times.

\subsection{Separation of Volatile Compounds}

Following evaluation of the 30 THSL samples, the volatile compounds were isolated using only the THSL sample considered to have the best sensory quality. An improved version of the Likens-Nickerson-type simultaneous distillation extraction (SDE) apparatus was used to extract the volatile compounds from the selected THSL $[10,21]$. SDE method was chosen because the procedures in this method are similar to that for preparing stewed THSL, a special dish of Hunan. For SDE, a $100 \pm 0.2 \mathrm{~g}$ THSL sample was cut into pieces $(\sim 1-2 \mathrm{~mm})$, mixed with $700 \mathrm{~mL}$ distilled water, and then loaded into a $1 \mathrm{~L}$ round-bottom flask located in the light phase section of the apparatus, and $50 \mu \mathrm{L}$ of 1,2-dichlorobenzene dichloromethane solution $(1.35 \mathrm{mg} / \mathrm{mL})$ was added. Redistilled dichloromethane $(50 \mathrm{~mL})$ was loaded into a $100 \mathrm{~mL}$ round-bottom flask in the dense phase section. The water phase was heated in a thermostatic oil bath (Yu Hua, GongYi, China) at $130^{\circ} \mathrm{C}$, and the solvent phase was heated in a thermostatic water bath at $50{ }^{\circ} \mathrm{C}$ to speed up the reflux and extraction of the water and solvent phases. Each sample was extracted for $4 \mathrm{~h}$ according to procedures described in our previous work [10]. The THSL extract was dried with anhydrous sodium sulfate and then concentrated to $1 \mathrm{~mL}$ with a Vigreux column. All experiments were repeated thrice.

\subsection{GC-MS and GC-O-MS Analysis}

The identification and quantification of the aroma compounds were conducted by using a Thermo Fisher Trace 1310 gas chromatograph coupled with a single quadrupole (ISQ) mass spectrometer (GC-MS) (Thermo Fisher, Waltham, MA, USA) in split ratios of 20:1. The GC-MS was equipped with a sniffing port (ODP3, Gerstel, Germany) (GC-O-MS) and the GC effluent was split 1:1 between the MS and sniffing port for the special structure of the GC-O-MS in splitless injection. The separation of the aroma compounds in the THSL extract was achieved on TG-5MS and TG-WAX columns (both $30 \mathrm{~m} \times 0.25 \mathrm{~mm}$ i.d. $\times 0.25 \mu \mathrm{m}$ film thicknesses, Thermo Fisher). Helium $(99.999 \%)$ was used as carrier gas at 1.200 and $1.600 \mathrm{~mL} / \mathrm{min}$ constant flow for GC-MS and GC-O-MS, respectively. The GC-MS and GC-O-MS analysis methods referenced in our previous work were used with some modifications [10,22].

The oven temperature of the TG-WAX column analysis was initially held at $40{ }^{\circ} \mathrm{C}$ for $3 \mathrm{~min}$ and was then increased to $100{ }^{\circ} \mathrm{C}$ at $8{ }^{\circ} \mathrm{C} / \mathrm{min}$, to $135^{\circ} \mathrm{C}$ at $6^{\circ} \mathrm{C} / \mathrm{min}$, held for $3 \mathrm{~min}$, and then increased 
again to $160^{\circ} \mathrm{C}$ at $1.5^{\circ} \mathrm{C} / \mathrm{min}$ and held for $3 \mathrm{~min}$ before being finally increased to $220^{\circ} \mathrm{C}$ at $3.6^{\circ} \mathrm{C} / \mathrm{min}$, which was held for $4 \mathrm{~min}$. The oven temperature of the TG-5MS column analysis was initially held at $50{ }^{\circ} \mathrm{C}$ for $1 \mathrm{~min}$ and was then increased to $150{ }^{\circ} \mathrm{C}$ at $2.5^{\circ} \mathrm{C} / \mathrm{min}$ and held for $2 \mathrm{~min}$; finally, it was increased to $220^{\circ} \mathrm{C}$ at $10^{\circ} \mathrm{C} / \mathrm{min}$ and held for $3 \mathrm{~min}$. The temperature of the sniffing port, injector, and ion source were kept at 230,250 , and $280^{\circ} \mathrm{C}$, respectively. Electronic-impact mass spectra ionization mode was used with an ionization energy of $70 \mathrm{eV}$ at full scan mode ( $\mathrm{m} / \mathrm{z}$ ranging from 40 to $450 \mathrm{amu}$ ).

\subsection{Aroma Extraction Dilution Analysis (AEDA)}

AEDA was used to characterize the flavor dilution (FD) factors of aroma-active compounds. The concentrated organic extract was diluted with dichloromethane solvent in a three-fold dilution series corresponding to $1: 3,1: 9, \ldots, 1: X$ dilutions. An aliquot of each dilution $(1 \mu \mathrm{L})$ was submitted to GC-O-MS with a TG-WAX column under the same GC conditions described in Section 2.5. All dilutions were repeated in triplicate by three panelists, and data were only recorded for aroma compounds that were detected in at least two replicates. The panelists underwent GC-O-MS training by sniffing 32 standards aroma compounds in a dichloromethane solvent $(\sim 50-500 \mu \mathrm{g} / \mathrm{kg})$ five times before this experiment.

\subsection{Identification and Quantification}

Identification of the aroma compounds was based on a comparison with the mass spectra (MS) database NIST 2014, retention indexes (RIs, on nonpolar and polar GC columns), pure standards (S), and odor characteristics $(\mathrm{O})$. Aroma-active compounds with FD $\geq 9$ were quantified using the standard curves with $50 \mu \mathrm{L}$ 1,2-dichlorobenzene $(1.35 \mathrm{mg} / \mathrm{mL})$ as internal standard. The correction coefficients of each aroma compound were calculated according to 1,2-dichlorobenzene internal standard. The detailed quantification procedures were performed according to our previous study $[23,24]$.

\subsection{Calculation of the Odor Activity Value}

The OAVs of aroma-active compounds were calculated by dividing the ratio of their concentration as measured in the THSL sample to their odor threshold as detected in water. These threshold values were referenced from the literature [25]. The unknown threshold values of the identified aroma-active compounds were detected by a triangular test according to the research measurement method [26]. Two odorless glass vessels $(40 \mathrm{~mL})$ filled with $20 \mathrm{~mL}$ odorless deionized water and another filled with an odorant standard solution were presented to 15 trained assessors who were asked to identify the differences among the 3 samples by a forced-choice test.

\subsection{Aroma Recombination}

Odorants with $\mathrm{OAV} \geq 1$ were dissolved in odorless capric triglyceride at concentration levels equal to those determined in the THSL sample. The recombination model and original THSL sample were evaluated using sensory tests according to the process in Section 2.3.

\subsection{Omission Tests}

To further validate the contribution of certain odorants to the overall aroma profile of the THSL, we prepared a series of omission models according to their high FD factors and high OAVs. Three samples comprising the omitted model and two complete recombination models, all encoded with 4 digital numbers, were presented to the panelists. The omitted model and complete reconstituted model were evaluated by quantitative descriptive analysis according to the process in Section 2.3 and triangle tests. 


\subsection{Statistical Analysis}

The sensory evaluation results for each aroma profile were analyzed using one-way analysis of variance (ANOVA) by SPSS 20.0 (SPSS Inc., Chicago, IL, USA). The correlation analysis of the recombination model and the THSL sample was conducted with Microsoft Excel 2016. The confidence interval of the ANOVA analysis, correlation analysis, and standard curve calculation was $95 \%$.

\section{Results and Discussion}

\subsection{Sensory Evaluation}

As the ranking analysis results show (Table 1), 10 THSL samples were selected from five groups, and the smoke-cured-18-day THSL (THSL-18) was evaluated to have the best sensory quality based on its high preference frequency of 14 . Thus, THSL-18 was selected as the raw material for further study (the QDA analysis and aroma identification experiments). The overall aroma profiles between the raw pork leg and THSL were also compared (Figure 2). A sour smell, pork aroma, and a strong bloody smell constituted the overall aroma of the raw pork (Figure 2a). However, after salt-curing and smoke-curing, the THSL had more complex and diverse aroma profiles, including woody, greasy, smoky, meaty, milky, spicy, and roasty (Figure $2 b$ ). The change in the aroma profile going from raw pork to THSL highlights that the salt-curing and smoke-curing processes increased the flavor of the raw pork. As previous studies have shown, many physical and biochemical reactions occur during smoke-cured meat product processing, including microbial fermentation [3], the Maillard reaction [4], lipid oxidation [5,7], Stecker degradation $[4,6]$, and smoke-curing $[7,26]$, leading to the generation of many aroma compounds. Therefore, the bloody and sour aroma attributes of the fresh pork were changed to woody, greasy, smoky, meaty, milky, spicy, and roasty attributes. These results show that food processing techniques can remove off-flavors and promote the aromatic quality of raw meat.

Table 1. The preference frequency results of the 10 traditional Hunan smoke-cured pork leg (THSL) samples with different smoke-curing times.

\begin{tabular}{ccccccccccc}
\hline Samples & THSL-5 & THSL-6 & THSL-11 & THSL-12 & THSL-17 & THSL-18 & THSL-19 & THSL-20 & THSL-25 & THSL-26 \\
\hline Frequency & 0 & 0 & 0 & 3 & 8 & 14 & 10 & 7 & 2 & 1 \\
\hline
\end{tabular}

Figure 2 shows that the dominant aroma attributes of THSL were meaty, smoky, roasty, woody, and greasy notes, which is significantly different from the dominant aroma profile of Guangdong bacon (with strong alcoholic, sweet, and sauce-like attributes) [27]. Smoke-cured bacon showed a lower intensity in its meaty, greasy, and roasty notes than those of the THSL [27]. Similar to the Jinhua ham, THSL also exhibited strong meaty and greasy notes. However, the other dominant aroma profiles of the ham included rancid flavor as well as cured, sour, and caramel flavors, which were different from the smoky, woody, roasty, and spicy characteristics of the THSL [28].

\subsection{GC-O/AEDA Analysis}

Through application of the GC-O/AEDA method, 39 aroma-active compounds (including 3 unknowns) with FD factors ranging from 9 to 6561, were identified in the THSL (Table 2). The chromatograms of the aroma compounds isolated from THSL on a TG-WAX column and the aroma-active compounds identified by GC-O/AEDA are shown in Figure 3. The major aroma-active compounds in the THSL were divided into two RI regions: 1200-1600 and 1900-2400 (Figure 3). In addition, most of the aroma-active compounds with high RIs exhibited higher FD factors. Among them, 3-ethylphenol ( $F D=6561$; leather and smoky) had the highest FD factor, which was consistent with a previous study that detected high aroma frequency and strong intensity in smoke-cured mini-pig [6]. However, 3-ethylphenol was determined to have a low FD factor of 32 in smoked cooked loin [9]. This might have resulted from the use of different smoke-curing techniques, given the smoked cooked loin was only smoke-cured for $20 \mathrm{~min}$, while the THSL was smoke-cured for 18 days and the smoke-cured 
mini-pig was smoke-cured for 1 month. Additionally, 3,4-dimethylphenol (FD = 2187; stink and leather) and 2,6-dimethoxyphenol (FD = 2187; leather and green) had the second-highest FD factors. It was reported that 2,6-dimethoxyphenol was also detected to have a high FD factor (128) in smoke-cured loin [9]. The 4-methylguaiacol (FD = 729; sweet, woody, caramel-like, and smoky), 4-ethylguaiacol (FD = 729; sweet, woody, caramel-like, and smoky), 2-methoxy-4-propyl-phenol (FD = 729; green, cool, fresh), 3-methylphenol (FD = 729; burning, leather, and stinky), and 2-methoxy-4-vinylphenol ( $\mathrm{FD}=729$; vanilla-like and smoky) ranked third in terms of their FD factors, followed by guaiacol ( $\mathrm{FD}=243$; woody, sweet, and caramel-like), 2-acetyl-1-pyrroline ( $\mathrm{FD}=243$; rice-like and cooked), 3,4,5-trimethoxytoluene ( $\mathrm{FD}=243$; bitter, earthy, and pungent), 2,5-dimethylphenol ( $\mathrm{FD}=243$; stinky and leathery), 2,3-dimethoxyphenol (FD = 243; rubber), and 3,5-dimethoxyphenol (FD = 243; rubber). Most of these aroma-active compounds with high FD factors were phenolic compounds.

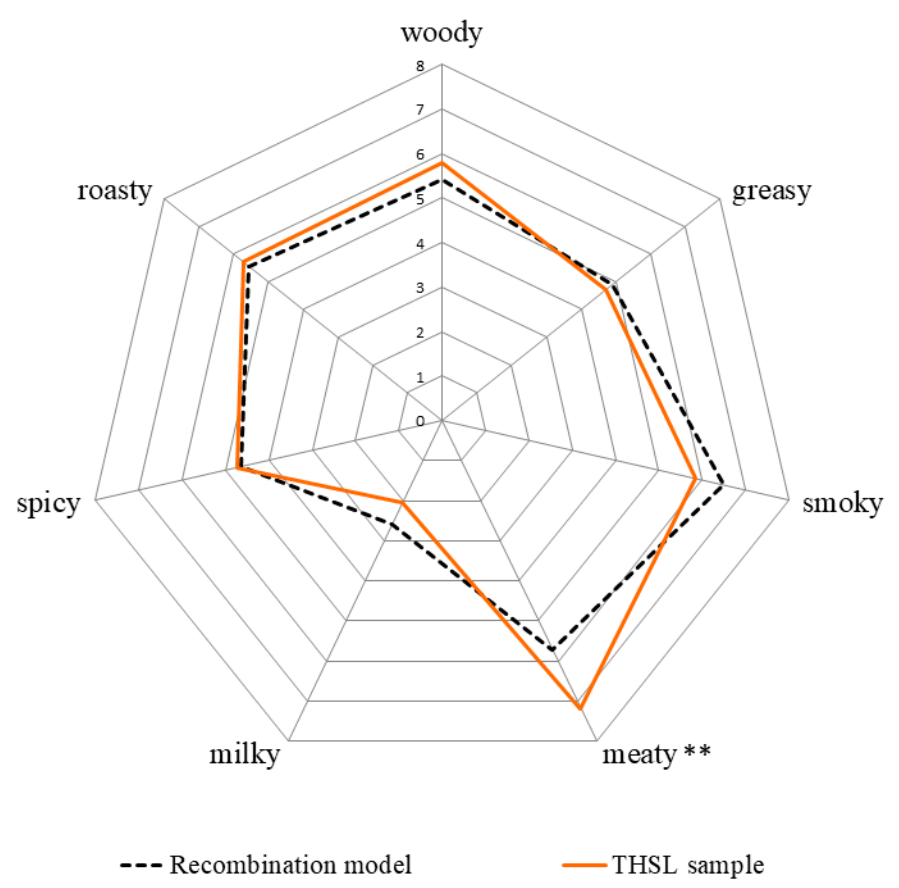

(a)

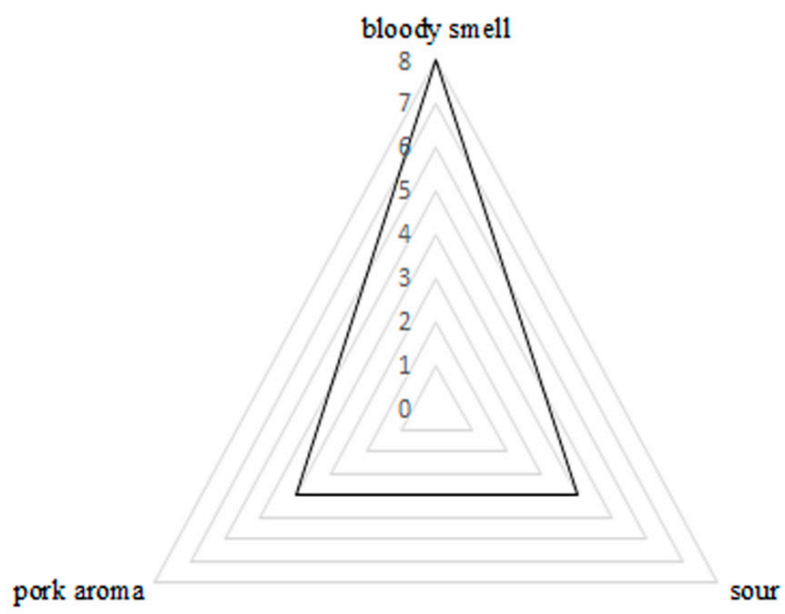

(b)

Figure 2. Quantitative descriptive analysis results of the traditional Hunan smoke-cured pork leg (THSL), along with its aroma recombination model (a) and the raw material of the pork leg (b). ${ }^{* *}$, the significance at $p<0.01$. 
Table 2. Aroma-active compounds identified in traditional Hunan Smoke-cured Pork Leg (THSL) by gas chromatography-olfactory-mass spectrometry (GC-O-MS).

\begin{tabular}{|c|c|c|c|c|c|c|}
\hline \multirow{2}{*}{ No. } & \multirow{2}{*}{ Compounds } & \multicolumn{2}{|c|}{ RI } & \multirow{2}{*}{ Identification } & \multirow{2}{*}{ FD Factors } & \multirow{2}{*}{ Odorant Descriptor } \\
\hline & & TG-WAX & TG-5MS & & & \\
\hline & Nitrogen compounds (3) & & & & & \\
\hline N1 & 2-Methylpyrazine & 1260 & 863 & MS, RI, S, O & 9 & roasty, nutty \\
\hline N2 & 2-Acetyl-1-pyrroline & 1316 & 921 & MS, RI, S, O & 729 & popcorn, grain, roasty \\
\hline N3 & $\begin{array}{l}\text { 2,3,5-Trimethylpyrazine } \\
\text { Aldehydes (3) }\end{array}$ & 1385 & 1024 & MS, RI, S, O & 81 & roasty, earthy \\
\hline A1 & Octanal & 1291 & 1023 & MS, RI, S, O & 9 & green, citrus \\
\hline A2 & (E)-2-Octenal & 1393 & 1078 & MS, RI, S, O & 81 & green leaf \\
\hline $\mathrm{A} 3$ & $\begin{array}{l}(E) \text {-2-Nonenal } \\
\text { Ketones }(6)\end{array}$ & 1589 & 1177 & MS, RI, S, O & 243 & peanut, almond, fatty \\
\hline K1 & 1-Octen-3-one & 1315 & - & MS, RI, S, O & 3 & mushroom \\
\hline $\mathrm{K} 2$ & 3-Methyl-2-cyclopenten-1-one & 1489 & 990 & MS, RI, S, O & 81 & sweet, fruity \\
\hline K3 & 3-Ethyl-2-cyclopenten-1-one & 1677 & - & MS, RI, S, O & 81 & caramel-like \\
\hline K4 & 4,4-Dimethyl-2-cyclopenten-1-one & 1768 & 964 & MS, RI, O & 27 & caramel-like, bitter \\
\hline K5 & 3-Methylacetophenone & 1790 & - & MS, RI, S, O & 9 & floral, sweet \\
\hline K6 & $\begin{array}{l}\text { 3-Ethyl-2-hydroxy-2-cyclopenten-1-one } \\
\text { Sulfur compound (1) }\end{array}$ & 1919 & 1136 & MS, RI, S, O & 81 & sweet, caramel-like \\
\hline S1 & $\begin{array}{c}\text { Methional } \\
\text { Furan compounds (2) }\end{array}$ & 1480 & 905 & MS, RI, S, O & 243 & cooked potato \\
\hline $\mathrm{F} 1$ & 2-Acetylfuran & 1483 & 938 & MS, RI, S, O & 27 & sweet, roast \\
\hline F2 & $\begin{array}{l}\text { 5-Methyl furfural } \\
\text { Unknow compounds (3) }\end{array}$ & 1593 & 986 & MS, RI, S, O & 27 & green, sweet, grass \\
\hline U1 & Unknown1 & - & - & $\mathrm{O}$ & 81 & bitter, medicine \\
\hline $\mathrm{U} 2$ & Unknown2 & - & - & $\mathrm{O}$ & 27 & cucumber, green, \\
\hline $\mathrm{U} 3$ & Unknown3 & - & - & $\mathrm{O}$ & 9 & green \\
\hline & Aromatic compounds (5) & & & & & \\
\hline B1 & 1-Methylnaphthalene & 1877 & 1300 & MS, RI, S, O & 81 & medicinal, sweet, vanilla-like \\
\hline B2 & 2-Methylnaphthalene & 1908 & 1299 & MS, RI, S, O & 27 & bitter \\
\hline B3 & 2-Ethylnaphthalene & 1962 & 1402 & MS, RI, S, O & 27 & burning \\
\hline $\mathrm{B} 4$ & 3,4-Dimethoxytoluene & 1987 & 1281 & MS, RI, O & 9 & green, dried grass \\
\hline B5 & 3,4,5-Trimethoxytoluene & 2069 & - & MS, RI, S, O & 243 & bitter, earth, pungent \\
\hline
\end{tabular}


Table 2. Cont.

\begin{tabular}{|c|c|c|c|c|c|c|}
\hline \multirow{2}{*}{ No. } & \multirow{2}{*}{ Compounds } & \multicolumn{2}{|c|}{ RI } & \multirow{2}{*}{ Identification } & \multirow{2}{*}{ FD Factors } & \multirow{2}{*}{ Odorant Descriptor } \\
\hline & & TG-WAX & TG-5MS & & & \\
\hline & Phenolic compounds (16) & & & & & \\
\hline P1 & Guaiacol & 1888 & 1104 & MS, RI, S, O & 243 & woody, sweet, smoky \\
\hline P2 & 2-Methoxy-6-methylphenol & 1897 & 1257 & MS, RI, O & 27 & woody, sweet \\
\hline P3 & 2,6-Dimethylphenol & 1937 & 1122 & MS, RI, S, O & 81 & smoky, burning \\
\hline $\mathrm{P} 4$ & 4-Methyl guaiacol & 1978 & 1208 & MS, RI, S, O & 729 & sweet, wood, caramel-like, smoky \\
\hline P5 & 2-Methylphenol & 2028 & 1076 & MS, RI, S, O & 27 & vanilla-like, woody \\
\hline P6 & 4-Ethyl guaiacol & 2048 & 1292 & MS, RI, S, O & 729 & wood, smoky, caramel-like \\
\hline P7 & 2,5-Dimethylphenol & 2099 & 1168 & MS, RI, S, O & 243 & butyric acid, stink, leather \\
\hline P8 & 3,4-Dimethylphenol & 2102 & 1194 & MS, RI, S, O & 2187 & butyric acid, stinky, leathery \\
\hline P9 & 3-Ethylphenol & 2105 & 1158 & MS, RI, S, O & 6561 & leathery, smoky \\
\hline $\mathrm{P} 10$ & 2-Methoxy-4-propyl-phenol & 2108 & 1382 & MS, RI, S, O & 729 & green, cool, fresh \\
\hline P11 & 3-Methylphenol & 2109 & 1095 & MS, RI, S, O & 729 & burning, leathery, stinky \\
\hline $\mathrm{P} 12$ & 3,5-Dimethoxyphenol & 2117 & 1189 & MS, RI, S, O & 243 & rubbery, butyric acid \\
\hline P13 & 2,3-Dimethoxyphenol & 2128 & - & MS, RI, S, O & 243 & rubbery, butyric acid \\
\hline $\mathrm{P} 14$ & 2-Methoxy-4-vinylphenol & 2208 & 1329 & MS, RI, S, O & 729 & vanilla-like, smoky, woody \\
\hline P15 & 2,6-Dimethoxyphenol & 2283 & 1370 & MS, RI, S, O & 2187 & leathery, green \\
\hline P16 & trans-2-Methoxy-4-propenyl-phenol & 2367 & 1382 & MS, RI, O & 81 & leathery, smoky \\
\hline
\end{tabular}

MS: identified by mass spectra; RI: calculated using a homologous series of $n$-alkanes $\left(\mathrm{C}_{6}-\mathrm{C}_{30}\right)$; S: identified by standards; O: odor characteristics of the aroma compounds; “-": not detected. 


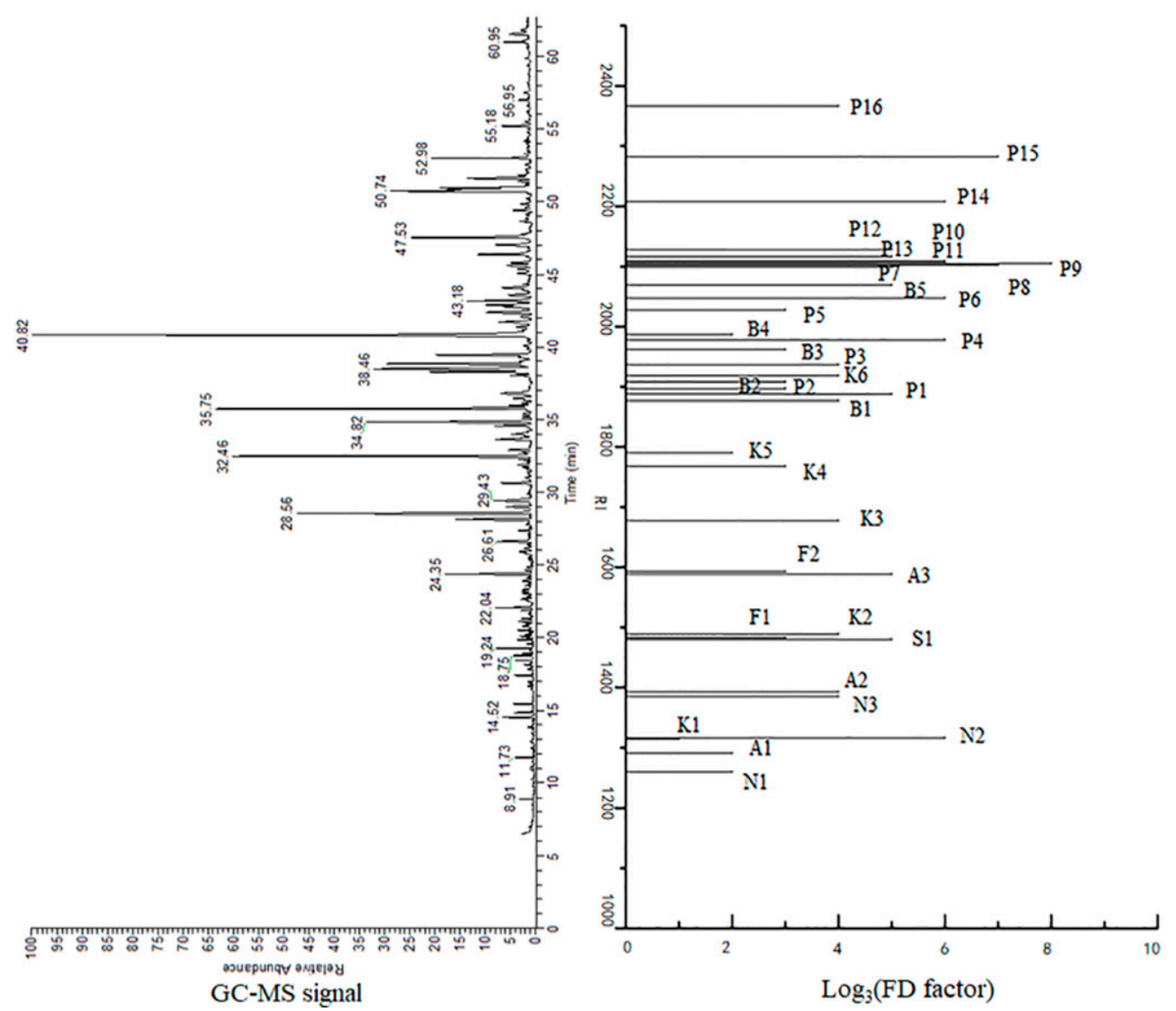

Figure 3. Aromagram and chromatogram of the volatiles isolated from traditional Hunan smoke-cured pork leg (THSL) with their flavor dilution (FD) factors and retention indexes (RIs) on a TG-WAX column according to Table 2 .

The phenolic compounds (P1-P16) with a high intensity of woody, pungent, and smoky characteristics were generated from lignin and phenolic acid degradation during wood-burning or enzymatic degradation by microorganisms [26]. Compared to previous research, these compounds that were detected in THSL were also found in other smoke-cured foods, such as smoked cooked loin [9], Hubei traditional smoke-cured bacon [11,12], Chongqing smoked-cured bacon [15], and traditional smoke-cured bacon of mini-pig [6]. These results are consistent with the previous identification of 3-ethylphenol as a key odorant in traditional smoke-cured bacon of mini-pig [6]. Guaiacol, 4-ethylguaiacol, and 4-methylguaiacol are important aroma-active compounds contributing to the smoky aroma of smoke-cured frankfurters and mini-salami [26]. These results indicate that phenolic compounds play a key role in the overall aroma profiles of THSL.

By contrast, 2-acetylfuran ( $\mathrm{FD}=27$; sweet and roast), octanal ( $\mathrm{FD}=9$; green and citrus), 2-methylpyrazine ( $\mathrm{FD}=9$; green and citrus), 3-methylacetophenone ( $\mathrm{FD}=9$; green and medicine), and 3,4-dimethoxytoluene ( $\mathrm{FD}=9$; green and dried grass) all had relatively lower FD factors. Six ketones (K1-K6) were detected in THSL, five of which had FD $\geq 9$. Among these ketones, 3-methyl-2-cyclopenten-1-one, 3-ethyl-2-cyclopenten-1-one, and 3-ethyl-2-hydroxy2-cyclopenten-1-one had the highest FD factors (81). Notably, 1-octen-3-one (FD = 3; mushroom) was determined to have the lowest FD factor of all characterized compounds in the THSL. As a previous study reported, many cyclopenten-1-one derivatives were generated during the high temperature degradation of wheat straw hemicellulose [29]. Therefore, 3-methyl-2-cyclopenten-1-one, 3-ethyl-2-cyclopenten-1-one, and 3-ethyl-2-hydroxy-2-cyclopenten-1-one, which present caramel-like and sweet characteristics in THSL, could be derived from wood-burning during the smoke-curing 
process. As previously reported, most of the methyl ketones, such as 3-hydroxy-2-butanone, 2,3-butanedione, and 2-heptanone in cooked meat, could be derived from lipid degradation [30].

Three nitrogenous compounds (N1-N3) were detected in THSL. 2-Acetyl-1-pyrroline, with an FD factor of 729, was detected here in THSL for the first time. An important aroma compound with roasty and cooked-rice characteristics, 2-acetyl-1-pyrroline can be derived via the Maillard reaction that occurs during fermentation or through smoke-curing (heating). It has been also identified as a critical odorant in rice [31,32], cooked lion [9,16], and bread [33]. Additionally, 2,3,5-trimethylpyrazine (81) and 2-methylpyrazine (9) were also detected in THSL. As previous studies have shown, pyrazines are the main byproduct of the Maillard reaction during the smoke-curing process [4,34]. Three aldehydes (A1-A3) were detected in THSL. (E)-2-Nonenal exhibited the highest FD factor with 243, followed by $(E)$-2-octenal $(\mathrm{FD}=81)$ and octanal $(\mathrm{FD}=9)$. Aliphatic aldehydes are mainly generated from the oxidation of unsaturated fatty acids in meat [34,35]. Aldehydes are important odorants contributing to the overall aroma profiles of THSL because of their low threshold values. Five aromatic compounds (B1-B5) were detected in THSL. 3,4,5-Trimethoxytoluene was found to have the highest FD factor of 243. These compounds were mainly derived from wood-burning during the smoke-curing process. Two furan compounds (F1-F2) were detected in THSL, including 2-acetylfuran and 5-methyl furfural with an FD factor of 27. Furan compounds were mainly generated from the Maillard reaction during the smoke-curing process and were also identified as potent odorants in meat products [3,4]. One sulfur compound (S1), methional, was detected in THSL with an FD factor of 243. Methional is produced from methionine with a high intensity of cooked potato characteristics with roasty attributes; it has been identified as a key odorant in smoke-cured mini-pig [6,9].

\subsection{Quantitation and Calculation of the $O A V$}

Thirty aroma-active compounds (FD $\geq 9$ ) were quantified in THSL. Their quantitative ions and standard curves are shown in Table S1. All calibration curves have good linearity because all correlation coefficients $\left(R^{2}\right)$ were over 0.99 . The concentrations and OAV results are presented in Table 3. Phenolic compounds exhibited the highest concentrations among all the compounds, including 2,6-dimethoxyphenol ( $9784.39 \mu \mathrm{g} / \mathrm{kg})$, 3,5-dimethoxyphenol $(4368.41 \mu \mathrm{g} / \mathrm{kg}), 2$-methoxy-4-vinylphenol (2761.99 $\mu \mathrm{g} / \mathrm{kg}), 2,6$-dimethylphenol $(2455.15 \mu \mathrm{g} / \mathrm{kg})$, and 2-methylphenol (2316.82 $\mu \mathrm{g} / \mathrm{kg})$. Most of the phenolic compounds with high FD factors exhibited significantly higher concentrations ( 597.00 to $12,710.00 \mu \mathrm{g} / \mathrm{kg}$ ) than other aroma compounds, indicating that they contribute to the overall aroma profiles of THSL [2,9]. However, the amounts of guaiacol, 4-ethylguaiacol, 3-ethylphenol, and 3-methylphenol in THSL were lower than those of smoked cooked loin (guaiacol, $1271.00 \mu \mathrm{g} / \mathrm{kg}$; 4-ethylguaiacol, $270.00 \mu \mathrm{g} / \mathrm{kg}$; 3-ethylphenol, $597.00 \mu \mathrm{g} / \mathrm{kg}$; and 3-methylphenol, $3529.00 \mu \mathrm{g} / \mathrm{kg})[6,9]$. The concentrations of 4-methylguaiacol $(1395.64 \mu \mathrm{g} / \mathrm{kg}), 4$-ethylguaiacol $(534.46 \mu \mathrm{g} / \mathrm{kg})$, and 3-methylphenol $(96.84 \mu \mathrm{g} / \mathrm{kg})$ were lower than the concentrations detected in mini-pig (4-methyl guaiacol, $1560.00 \mu \mathrm{g} / \mathrm{kg}$; 4-ethylguaiacol, $1120.00 \mu \mathrm{g} / \mathrm{kg}$; 3-methylphenol, $5140.00 \mu \mathrm{g} / \mathrm{kg}$ ). Most of the phenolic compounds exhibited higher OAVs, which is consistent with previous studies $[6,9,11]$.

In contrast to the compounds of a high concentration, 2,3,5-trimethylpyrazine ( $204.69 \mu \mathrm{g} / \mathrm{kg})$, 2-methylpyrazine $(142.89 \mu \mathrm{g} / \mathrm{kg})$, methional $(98.58 \mu \mathrm{g} / \mathrm{kg})$, 3-methyl-2-cyclopenten-1-one $(96.63 \mu \mathrm{g} / \mathrm{kg})$, and octanal $(76.77 \mu \mathrm{g} / \mathrm{kg})$ were measured to have a lower concentration in THSL. Here, 2-acetyl-1-pyrroline $(38.88 \mu \mathrm{g} / \mathrm{kg})$ was first identified for the first time in smoke-cured pork leg. Though this aroma compound had a lower concentration in THSL, its low threshold value suggests its potential contribution to the overall aroma of THSL. Among the aroma-active compounds, the percentage of phenolic compounds $(83.67 \%)$ was the highest, followed by aromatic compounds $(10.02 \%)$, furan $(2.15 \%)$, ketones $(1.59 \%)$, aldehydes $(1.14 \%)$, nitrogen compounds $(1.14 \%)$, and sulfur compounds $(0.29 \%)$. These results also suggest that phenolic compounds are the dominant aroma compounds in THSL. 
Table 3. Concentrations and odor activity values (OAVs) of the aroma-active compounds detected in traditional Hunan smoke-cured pork leg (THSL).

\begin{tabular}{|c|c|c|c|c|}
\hline No. & Odorants & $\begin{array}{c}\text { Concentration } \\
(\mu \mathrm{g} / \mathrm{kg})\end{array}$ & $\begin{array}{c}\text { Threshold } \\
(\mu \mathrm{g} / \mathrm{kg})\end{array}$ & OAV \\
\hline A1 & (E)-2-Nonenal & $279.75 \pm 11.13$ & $0.19^{a}$ & 1472 \\
\hline $\mathrm{A} 2$ & (E)-2-Octenal & $30.42 \pm 1.54$ & $4.00^{b}$ & 8 \\
\hline $\mathrm{A} 3$ & Octanal & $76.77 \pm 22.61$ & $3.40^{\mathrm{a}}$ & 23 \\
\hline Total & Aldehydes & 386.94 & & \\
\hline $\mathrm{P} 1$ & Guaiacol & $1225.46 \pm 72.44$ & $2.50^{\mathrm{a}}$ & 490 \\
\hline P3 & 2,6-Dimethylphenol & $2455.15 \pm 191.36$ & $14.20^{\mathrm{c}}$ & 173 \\
\hline $\mathrm{P} 4$ & 4-Methyl guaiacol & $1395.64 \pm 62.82$ & $25.00^{\mathrm{a}}$ & 56 \\
\hline P5 & 2-Methylphenol & $2316.82 \pm 248.34$ & $45.00^{\mathrm{a}}$ & 52 \\
\hline P6 & 4-Ethyl guaiacol & $534.46 \pm 41.54$ & $16.00^{\mathrm{a}}$ & 33 \\
\hline P7 & 2,5-Dimethylphenol & $811.64 \pm 55.08$ & $400.00^{c}$ & 2 \\
\hline P8 & 3,4-Dimethylphenol & $653.04 \pm 59.91$ & $17.00^{c}$ & 38 \\
\hline P9 & 3-Ethylphenol & $344.81 \pm 5.97$ & $1.70^{\mathrm{a}}$ & 203 \\
\hline P10 & 2-Methoxy-4-propyl-phenol & $510.51 \pm 80.98$ & $157.00^{\mathrm{c}}$ & 3 \\
\hline P11 & 3-Methylphenol & $96.84 \pm 14.66$ & $15.00^{\mathrm{a}}$ & 6 \\
\hline P12 & 3,5-Dimethoxyphenol & $4368.41 \pm 435.16$ & $140.00^{c}$ & 31 \\
\hline P13 & 2,3-Dimethoxyphenol & $1100.40 \pm 30.37$ & $170.00^{\mathrm{c}}$ & 6 \\
\hline P14 & 2-Methoxy-4-vinylphenol & $2761.99 \pm 39.96$ & $5.10^{\mathrm{a}}$ & 542 \\
\hline P15 & 2,6-Dimethoxyphenol & $9784.39 \pm 852.69$ & $263.00^{a}$ & 37 \\
\hline Total & Phenolic compounds & $28,359.56$ & & \\
\hline N1 & 2-Methylpyrazine & $142.89 \pm 55.24$ & $250.00^{a}$ & $<1$ \\
\hline N2 & 2-Acetyl-1-pyrroline & $38.88 \pm 5.32$ & $0.12^{b}$ & 324 \\
\hline N3 & 2,3,5-Trimethylpyrazine & $204.69 \pm 52.35$ & $71.00^{\mathrm{a}}$ & 3 \\
\hline Total & Nitrogen compounds & 386.46 & & \\
\hline B1 & 1-Methylnaphthalene & $693.08 \pm 48.08$ & $10.75^{c}$ & 65 \\
\hline B2 & 2-Methylnaphthalene & $206.49 \pm 9.39$ & $4.00^{\mathrm{c}}$ & 52 \\
\hline B3 & 2-Ethylnaphthalene & $222.57 \pm 7.78$ & $4.96^{\mathrm{c}}$ & 55 \\
\hline B5 & 3,4,5-Trimethoxytoluene & $2275.00 \pm 29.69$ & $120.00^{c}$ & 19 \\
\hline Total & Aromatic compounds & 3397.14 & & \\
\hline S1 & Methional & $98.58 \pm 8.18$ & $1.80^{\mathrm{a}}$ & 55 \\
\hline Total & Sulfur compound & 98.58 & & \\
\hline $\mathrm{K} 2$ & 3-Methyl-2-cyclopenten-1-one & $96.63 \pm 52.23$ & $300.00^{b}$ & $<1$ \\
\hline K5 & 3-Methylacetophenone & $236.84 \pm 20.57$ & $123.25^{c}$ & 2 \\
\hline K6 & 3-Ethyl-2-hydroxy-2-cyclopenten-1-one & $205.09 \pm 86.55$ & $53.35^{c}$ & 4 \\
\hline Total & Ketone compounds & 538.56 & & \\
\hline F1 & 2-Acetylfuran & $595.46 \pm 35.50$ & $1000.00^{\mathrm{a}}$ & $<1$ \\
\hline F2 & 5-Methyl furfural & $133.84 \pm 4.43$ & $50.00^{\mathrm{b}}$ & 3 \\
\hline Total & Furan compounds & 729.30 & & \\
\hline
\end{tabular}

a Odorant threshold values from Czerny, Christlbauer, Christlbauer, Fischer, Granvogl, Hernandez, and Schieberle (2008); ${ }^{b}$ Odorant threshold values from (Burdock, 2010); ${ }^{\mathrm{c}}$ Odorant thresholds (in water) detected according to Czerny et al. (2008).

To obtain deeper insight into the contribution of aroma-active compounds to the overall aroma profile of THSL, their OAVs (the ratio of concentration to odor threshold) were calculated. There were 27 odorants with OAVs $\geq 1$ in THSL (Table 3), but 3 compounds (2-methylpyrazine, 2-acetylfuran, and 3-methyl-2-cyclopenten-1-one) had $\mathrm{OAVs}<1$, indicating that they were insignificant to the overall aroma of THSL. These 24 odorants with OAVs in the range of 2-1472 were potent odorants for THSL aroma. $(E)-2-N o n e n a l$ had the highest OAV $(\mathrm{OAV}=1472)$ due to its significantly low odor threshold value $(0.19 \mu \mathrm{g} / \mathrm{kg})$, followed by 2-methoxy-4-vinylphenol (OAV = 542), guaiacol $(\mathrm{OAV}=490)$, 2-acetyl-1-pyrroline (OAV = 324), 3-ethylphenol (OAV = 203), 2,6-dimethylphenol (OAV = 173), and $(E)$-2-octenal $(\mathrm{OAV}=106)$. The results show that the overall aroma profiles of THSL consist of various aroma compounds with higher OAVs that provide more important contributions to the overall aroma. 


\subsection{Recombination Result}

An aroma recombination experiment was conducted to validate the identification and quantification of the aroma-active compounds in THSL. All odorants with OAVs $\geq 1$ were dissolved in an odorless capric triglyceride solution according to their measured concentrations. The sensory evaluation results of the recombination model and the THSL sample are shown in Figure 2a. A correlation analysis showed a $90.73 \%$ similarity between the recombination model and the THSL sample. However, there remained some differences between the milky, meaty, and smoky attributes. High significant difference $(p<0.01)$ in meaty attribute between the recombination model and THSL sample was observed. This might be due to the aroma compounds with meaty characteristic being digested or not being captured during SDE extraction.

\subsection{Omission Test}

To further corroborate the contributions of the potent odorants with OAVs $\geq 1$ and to determine which compound are key odorants, 12 aroma omission models $\left(\mathrm{M}_{1}-\mathrm{M}_{12}\right)$ were prepared. The results of the omission tests are shown in Table 4. A total of nine omission models were significantly different from the complete recombination models. In $\mathrm{M}_{1}$, the entire group of phenolic compounds was omitted due to their high FD factors and high OAVs. All panelists correctly detected the differences between the omitted model $\left(\mathrm{M}_{1}\right)$ and the complete recombination model. The intensity of the smoky attribute was significantly $(p<0.001)$ decreased when the phenolic compounds were omitted, which indicates that phenolic compounds played an important role in the smoky notes of THSL. 2-Methoxy-4-vinylphenol, guaiacol, 3-ethylphenol, and 2,6-dimethylphenol, characterized by high FD factors and high OAVs, were also omitted in the four omission models of $\mathrm{M}_{9}, \mathrm{M}_{10}, \mathrm{M}_{11}$, and $\mathrm{M}_{12}$, respectively. The results showed that 14,13,13, and 12 panelists, respectively, were able to correctly detect the differences between the complete model and the omission models when these compounds were omitted (Table 4). However, they showed a different degree of contributions to the aroma profile of THSL due to their different properties. Over 13 out of 15 panelists detected the differences between the omitted model and the complete model when either 2-methoxy-4-vinylphenol or guaiacol were omitted. The intensities of the smoky and roasty attributes of the omitted models were also significantly decreased $(p<0.001)$. Therefore, 2-methoxy-4-vinylphenol and guaiacol were confirmed to be key odorants of THSL. In addition, significant differences $(p<0.01)$ between the omission models $\left(\mathrm{M}_{11}\right.$ and $\left.\mathrm{M}_{12}\right)$ and the complete recombination model were observed, demonstrating that 3-ethylphenol and 2,6-dimethylphenol were also the key odorants of THSL, contributing to the smoky attribute. These results are consistent with those of previous studies, which showed that phenolic compounds play key roles in the smoky aroma of smoke-cured meat products $[2,6,9,11]$. Moreover, single phenolic compounds, including 2-methoxy-4-vinylphenol $\left(\mathrm{M}_{9}\right)$, guaiacol $\left(\mathrm{M}_{10}\right)$, 3-ethylphenol $\left(\mathrm{M}_{11}\right)$, and 2,6-dimethylphenol $\left(\mathrm{M}_{12}\right)$, were all confirmed to be key odorants of THSL. These conclusions are also in good agreement with the high OAVs and high FD factors determined for these compounds.

In $\mathrm{M}_{2}$, the entire group of ketone compounds was omitted due to their sweet and caramel-like characteristics. No significant difference was observed by the panelists between the complete recombination model and the omitted model of $\mathrm{M}_{2}$. This indicates that ketones are not the key odorants in THSL, which might be due to their lower OAVs. A similar result was observed when a group of aromatic compounds was omitted in $\mathrm{M}_{4}$, suggesting that aromatic compounds were also not key odorants in THSL. In $\mathrm{M}_{3}$, all of the aldehydes were omitted due to their high OAVs. In the results, 14 of 15 panelists could correctly detect the difference between the complete recombination model and the omitted model $\left(\mathrm{M}_{3}\right)$. In addition, the intensity of the greasy attribute decreased significantly when aldehydes were omitted, suggesting that aldehydes contributed greatly to the greasy aroma of THSL. $(E)-2-N o n e n a l(\mathrm{OAV}=1472)\left(\mathrm{M}_{6}\right)$ and octanal $(\mathrm{OAV}=23)\left(\mathrm{M}_{7}\right)$ were further omitted to determine whether they play important roles in THSL aroma. In $\mathrm{M}_{6}$, a significant decrease $(p<0.001)$ in the intensity of greasy characteristics was observed by 14 of 15 panelists when $(E)$-2-nonenal was 
omitted, suggesting that $(E)$-2-nonenal is a key odorant in THSL. However, no significant difference was observed when octanal was omitted.

Table 4. Results of the omission tests.

\begin{tabular}{ccccc}
\hline No. & Aroma Profile Descriptions & Omitted Compounds & $\begin{array}{c}\text { Correct Number } \\
\text { in All }\end{array}$ & Significance \\
\hline $\mathrm{M}_{1}$ & Smoky, leathery & All of the phenolic compounds & $15 / 15$ & $* * *$ \\
$\mathrm{M}_{2}$ & Caramel-like, sweet & All of the ketone compounds & $7 / 15$ & - \\
$\mathrm{M}_{3}$ & Green, grass, fatty & All of the aldehyde compounds & $14 / 15$ & $* * *$ \\
$\mathrm{M}_{4}$ & Bitter, leathery & All of the aromatic compounds & $8 / 15$ & - \\
$\mathrm{M}_{5}$ & Popcorn, grain, roasty & 2-acetyl-1-pyrroline & $14 / 15$ & $* * *$ \\
$\mathrm{M}_{6}$ & Peanut, almond, fatty & (E)-2-nonenal & $14 / 15$ & $* *$ \\
$\mathrm{M}_{7}$ & green, citrus & octanal & $10 / 15$ & - \\
$\mathrm{M}_{8}$ & Cooked potato & methional & $12 / 15$ & $* *$ \\
$\mathrm{M}_{9}$ & Vanilla-like, smoky, woody & 2-methoxy-4-vinylphenol & $14 / 15$ & $* * *$ \\
$\mathrm{M}_{10}$ & Woody, sweet, smoky & guaiacol & $13 / 15$ & $* * *$ \\
$\mathrm{M}_{11}$ & Leathery, smoky & 3-ethylphenol & $13 / 15$ & $* *$ \\
$\mathrm{M}_{12}$ & Leathery, green & 2,6-dimethylphenol & $12 / 15$ & $* *$ \\
\hline$* * *$ significance level $p<0.001 ; * *$ significance level $p<0.01 ;-$ no significant difference. The confidence interval & &
\end{tabular}

As previous studies have reported, 2-acetyl-1-pyrroline with a high FD factor is a key odorant in rice, bread, Jinhua ham, and smoked cooked lion $[9,32,33,36]$. Here, it was detected in THSL for the first time and had the fourth-highest OAV among all odorants in the THSL. A mixture of all the odorants, except for 2-acetyl-1-pyrroline, was produced for the $\mathrm{M}_{5}$. The triangle test showed that highly significant differences $(p<0.001)$ exist between the complete recombination sample and $\mathrm{M}_{5}$ and that 2-acetyl-1-pyrroline is a key odorant in THSL. In $\mathrm{M}_{8}$, the odorant with a high FD factor of 243 and a high intensity of cooked potato aroma was omitted. Twelve out of fifteen panelists correctly detected a distinction between the $\mathrm{M}_{8}$ and complete recombination models. A significant difference $(p<0.01)$ in the roasty attribute between the omitted model and the complete recombination model was observed, indicating that methional was the key odorant in THSL.

In summary, seven compounds, including methional, contributing to roasty notes; 3-ethylphenol, guaiacol, 2,6-dimethylphenol, and 2-methoxy-4-vinylphenol, contributing to smoky notes; (E)-2-nonenal, contributing to greasy notes; and 2-acetyl-1-pyrroline were confirmed as key odorants in THSL.

\section{Conclusions}

After salt-curing and smoke-curing, THSL had a more complex and diverse aroma profile, including meaty, woody, greasy, smoky, milky, spicy, and roasty notes. Through the application of GC-O/AEDA, 39 aroma-active compounds were detected, 30 of which were further quantified using standard curves. Twenty-seven odorants with $\mathrm{OAV} \geq 1$ were obtained. Among them, $(E)$-2-nonenal $(\mathrm{OAV}=1,472)$, 2-methoxy-4-vinylphenol $(\mathrm{OAV}=542)$, guaiacol $(\mathrm{OAV}=490)$, 2-acetyl-1-pyrroline (OAV $=324)$, 3-ethylphenol $(\mathrm{OAV}=203)$, and 2,6-dimethylphenol $(\mathrm{OAV}=173)$ showed the highest OAVs. The recombination model had a $90.73 \%$ similarity with the original THSL sample, which validated the characterization of the aroma compounds in THSL. Omission experiments further confirmed that (E)-2-nonenal, 2-methoxy-4-vinylphenol, 3-ethylphenol, guaiacol, methional, 2-acetyl-1-pyrroline, and 2,6-dimethylphenol were key odorants in THSL. In addition, 2-acetyl-1-pyrroline was confirmed as the key odorant contributor of roasty in THSL for the first time.

Supplementary Materials: The following are available online at http://www.mdpi.com/2304-8158/9/4/413/s1, Table S1: Standard curves of the aroma-active compounds.

Author Contributions: D.P.: Investigation; methodology; writing-review and editing; Y.Z.: Investigation; methodology; writing-review and editing; H.Z.: Sample pretreatment; B.S.: Resources; F.R.: Resources; H.C.: Investigation; Y.T.: Writing - review and editing. All authors have read and agreed to the published version of the manuscript. 
Funding: This work was supported by the Beijing Outstanding Young Scientist Program (No. BJJWZYJH01201910011025), the National Natural Science Foundation of China (No. 31972191), the National Key R\&D Program of China (No. 2016YFD0400705), and the School Level Cultivation Fund of Beijing Technology and Business University for Distinguished and Excellent Young Scholars (No. BTBUYP2020).

Conflicts of Interest: The authors declare that they have no conflicts of interest.

\section{References}

1. Zeng, W.; Wen, W.; Deng, Y.; Tian, Y.; Sun, H.; Sun, Q. Chinese ethnic meat products: Continuity and development. Meat Sci. 2016, 120, 37-46. [CrossRef]

2. Lawless, H.T.; Heymann, H. Sensory Evaluation of Food: Principles and Practices; Springer Science \& Business Media: Berlin, Germany, 2013.

3. Diez-Simon, C.; Mumm, R.; Hall, R.D. Mass spectrometry-based metabolomics of volatiles as a new tool for understanding aroma and flavour chemistry in processed food products. Metabolomics 2019, 15, 41. [CrossRef] [PubMed]

4. Mottram, D.S. Flavour formation in meat and meat products: A review. Food Chem. 1988, 62, 415-424. [CrossRef]

5. Huang, Y.; Li, H.; Huang, T.; Li, F.; Sun, J. Lipolysis and lipid oxidation during processing of Chinese traditional smoke-cured bacon. Food Chem. 2014, 149, 31-39. [CrossRef] [PubMed]

6. Xie, J.C.; Sun, B.G.; Wang, S.B. Aromatic Constituents from Chinese Traditional Smoke-curing Bacon of Mini-pig. J. Food Sci. Technol. 2008, 14, 329-340. [CrossRef]

7. Yang, Y.; Zhang, X.; Wang, Y.; Pan, D.; Sun, Y.; Cao, J. Study on the volatile compounds generated from lipid oxidation of Chinese bacon (unsmoked) during processing. Eur. J. Lipid Sci. Technol. 2017, 119, 1600512. [CrossRef]

8. Dunkel, A.; Steinhaus, M.; Kotthoff, M.; Nowak, B.; Krautwurst, D.; Schieberle, P.; Hofmann, T. Nature's Chemical Signatures in Human Olfaction: A Foodborne Perspective for Future Biotechnology. Angew. Chem. Int. Edit. 2014, 53, 7124-7143. [CrossRef] [PubMed]

9. Kosowska, M.; Majcher, M.A.; Jelen, H.H.; Fortuna, T. Key aroma compounds in smoked cooked Lion. J. Agric. Food Chem. 2018, 66, 3683-3695. [CrossRef]

10. Pu, D.D.; Sun, J.; Chen, H.T.; Sun, B.G.; Zhang, Y.Y. Comparative Analysis of Volatile Flavor Compounds of Cooked Hunan and Guangdong Bacon by Simultaneous Distillation and Extraction Combine with Gas Chromatography-Mass Spectrometry (SDE-GC-MS) and Gas Chromatography-Olfactometry (GC-O). Food Sci. 2015, 36, 131-136.

11. Yu, N.; Sun, B.G. Flavour substances of Chinese traditional smoke-curing bacon. Food Chem. 2005, 89, 227-233.

12. Yu, N.; Sun, B.G.; Tian, D.; Qu, W. Analysis of volatile compounds in traditional smoke-curing bacon (CSCB) with different fiber coatings using SPME. Food Chem. 2008, 110, 233-238. [CrossRef] [PubMed]

13. Shang, Y.B.; Wu, J.F.; Xia, Y.Y.; Tu, D.W. Changes of Volatile Flavor Compounds in Traditional Chinese Bacon during Cold Smoking. Food Sci. 2009, 30, 79-83.

14. Zhang, S.L.; Wang, S.W.; Chen, X.Y.; Song, Z.X.; Hao, B.R.; Qiao, X.L.; Chen, W.H.; Qu, C. Changes in volatile flavor components during hunan cured meat processing. Food Sci. 2015, 36, 215-219.

15. Zhong, Y.R.; Zhou, H.; Lou, A.H.; Lou, Q.W.; Liu, C.G. Comparison between Volatile Compounds in Fast, Factory Dry-smoked and Traditional Air Dry-smoked Xiang-xi Chinese Bacon. Mod. Food Sci. Technol. 2015, 31, 361-371.

16. Saldaña, E.; Saldarriaga, L.; Cabrera, J.; Siche, R.; Behrens, J.H.; Selani, M.M.; Contreras-Castillo, C.J. Relationship between volatile compounds and consumer-based sensory characteristics of bacon smoked with different Brazilian woods. Food Res. Int. 2018, 119, 839-849. [CrossRef]

17. Poligné, A.; Collignan, G. Trystram, Effects of Salting, Drying, Cooking, and Smoking Operations on Volatile Compound Formation and Color Patterns in Pork. J. Food Sci. 2010, 67, 2976-2986. [CrossRef]

18. Li, Y.Y.; Song, Y.Q.; Li, H.N.; Guo, W.P.; Wang, S.W. Analysis of Main Rancid Compounds from Cured Meat Products by solid-phase microextraction-Gas Chromatography-Mass Spectrometry. Meat Res. 2014, $28,11-14$. 
19. Li, X.; Zhu, J.; Li, C.; Ye, H.; Wang, Z.; Wu, X.; Xu, B. Evolution of Volatile Compounds and Spoilage Bacteria in Smoked Bacon during Refrigeration Using an E-Nose and GC-MS Combined with Partial Least Squares Regression. Molecules 2018, 23, 3286. [CrossRef]

20. Liu, H.L.; Sun, B.G. Effect of fermentation processing on the flavor of Baijiu. J. Agric. Food Chem. 2018, 66, 5425-5432. [CrossRef]

21. Cai, B.; Liu, B.Z.; Su, Q.D. Comparison of simultaneous distillation extraction and solid-phase microextraction for the determination of volatile flavor components. J. Chromatog. A 2011, 930, 1-7. [CrossRef]

22. Hübschmann, H.J. Handbook of GC-MS: Fundamentals and Applications; John Wiley \& Sons: Hoboken, NJ, USA, 2015.

23. Pu, D.D.; Zhang, H.Y.; Zhang, Y.Y.; Sun, B.G.; Ren, F.Z.; Chen, H.T. Characterization of the key aroma compounds in white bread by aroma extract dilution analysis, quantitation, and sensory evaluation experiments. J. Food Process. Preserv. 2009, 43, e13933. [CrossRef]

24. Zhang, H.Y.; Pu, D.D.; Sun, B.G.; Ren, F.Z.; Zhang, Y.Y.; Chen, H.T. Characterization and comparison of key aroma compounds in raw and dry porcini mushroom (Boletus edulis) by aroma extract dilution analysis, quantitation and aroma recombination experiments. Food Chem. 2018, 258, 260-268. [CrossRef] [PubMed]

25. Czerny, M.; Christlbauer, M.; Christlbauer, M.; Fischer, A.; Granvogl, M.; Hernandez, M.; Schieberle, P. Re-investigation on odour thresholds of key food aroma compounds and development of an aroma language based on odour qualities of defined aqueous odorant solutions. Eur. Food Res. Technol. 2008, 228, 265-273. [CrossRef]

26. Hitzel, A.; Pöhlmann, M.; Schwägele, F.; Speer, K.; Jira, W. Polycyclic aromatic hydrocarbons (PAH) and phenolic substances in meat products smoked with different types of wood and smoking spices. Food Chem. 2013, 139, 955-962. [CrossRef]

27. Wang, H.; Zhang, X.; Suo, H.; Zhao, X.; Kan, J. Aroma and flavor characteristics of commercial Chinese traditional bacon from different geographical regions. J. Sens. Stud. 2018, 34, e12475. [CrossRef]

28. Bi, Y.; Zhou, G.H.; Pan, D.D.; Wang, Y.; Dang, Y.L.; Liu, J.H.; Jiang, M.F.; Cao, J.X. The effect of coating incorporated with black pepper essential oil on the lipid deterioration and aroma quality of Jinhua ham. J. Food Meas. Charact. 2019, 13, 2740-2750. [CrossRef]

29. Peng, Y.; $\mathrm{Wu}, \mathrm{S}$. The structural and thermal characteristics of wheat straw hemicellulose. J. Anal. Appl. Pyrol. 2010, 88, 134-139. [CrossRef]

30. Belitz, H.D.; Grosch, W.; Schieberle, P. Food Chemistry, 4th ed.; Springer: Berlin, Germany, 2009.

31. Wongpornchai, S.; Sriseadka, T.; Choonvisase, S. Identification and Quantitation of the Rice Aroma Compound, 2-Acetyl-1-pyrroline, in Bread Flowers (Vallaris glabra Ktze). J. Agric. Food Chem. 2003, 51, 457-462. [CrossRef]

32. Wei, X.; Handoko, D.D.; Pather, L.; Methven, L.; Elmore, J.S. Evaluation of 2-acetyl-1-pyrroline in foods, with an emphasis on rice flavor. Food Chem. 2017, 232, 531-544. [CrossRef]

33. Schieberle, P.; Grosch, W. Quantitative analysis of aroma compounds in wheat and rye bread crusts using a stable isotope dilution assay. J. Agric. Food Chem. 1987, 35, 252-257. [CrossRef]

34. Takakura, Y.; Sakamoto, T.; Hirai, S.; Masuzawa, T.; Wakabayashi, H.; Nishimura, T. Characterization of the key aroma compounds in beef extract using aroma extract dilution analysis. Meat Sci. 2014, 97, $27-31$. [CrossRef] [PubMed]

35. Shahidi, F.; Rubin, L.J.; D'Souza, L.A.; Teranishi, R.; Buttery, R.G. Meat flavor volatiles: A review of the composition, techniques of analysis, and sensory evaluation. Crit. Rev. Food Sci. 1986, 24, 141-243. [CrossRef] [PubMed]

36. Song, H.L.; Cadwallader, K.R. Aroma Components of American Country Ham. J. Food Sci. 2007, 73, 29-35. [CrossRef] [PubMed]

(C) 2020 by the authors. Licensee MDPI, Basel, Switzerland. This article is an open access article distributed under the terms and conditions of the Creative Commons Attribution (CC BY) license (http://creativecommons.org/licenses/by/4.0/). 